\title{
PINTANDO O MORRO: A COR NA PREFERÊNCIA VISUAL PERCEBIDA EM FACHADAS DE CASAS POPULARES
}

\author{
Maria Carolina Leitão Adeodato (discente) / UFPE \\ Lourival Costa Filho (orientador) / UFPE
}

\section{RESUMO}

A pesquisa ora apresentada busca avaliar a cor na preferência visual percebida em fachadas de casas populares dos morros das grandes cidades. Através do Sistema de Classificações Múltiplas, com moradores desses locais pretende-se explorar os principais conceitos que esse grupo utiliza para avaliar a cor em fachadas de casas populares e identificar as dimensões da cor (matiz, saturação, luminosidade) relacionadas com a preferência visual percebida. Considerando que esse tipo de avaliação influencia o comportamento, espera-se, como principal resultado esperado, que essa pesquisa em desenvolvimento possa responder aos objetivos traçados e, assim, favorecer a experiência visual das pessoas em relação às fachadas das casas populares nos morros das grandes cidades brasileiras. Caso se confirme a premissa de a cor proporcionar bem-estar, sentimento de pertencimento, memórias e significados, pode-se propor ações de melhoria da qualidade de vida - de moradores dos morros das grandes cidades brasileiras - ao se colorir as fachadas das suas casas.

Palavras-chave: Estética ambiental; Efeito da cor; Fachadas de casas populares; Percepção cromática.

\section{Introdução}

As características ambientais - entre elas a cor - têm importantes impactos na experiência humana, podendo evocar fortes emoções, como prazer ou desprazer, atuar como efeito atraente ou calmante, e possibilitar inferências sobre lugares e pessoas. Podem também influenciar o comportamento humano, de modo que as pessoas estejam mais propensas a visitar locais que percebem favoravelmente, e a evitar outros que julguem desfavoráveis. Nesse contexto, através do Programa Mais Vida no Morro, capitaneado por uma parceria público-privada, há uma intervenção nos morros da cidade do Recife, no Estado de Pernambuco, Brasil, que, além de outras ações, os moradores da comunidade puderam escolher a cor e pintar as fachadas das suas casas. Morro Burity (Figura 1), após intervenção do Programa Mais Vida no Morro. Portanto, esta pesquisa - em desenvolvimento tem como objetivo geral avaliar a cor na preferência visual percebida em fachadas de casas populares, e como objetivos específicos compreender o que norteia a escolha das cores das fachadas das casas populares e identificar as dimensões da cor (matiz, saturação, luminosidade) relacionadas com a preferência visual percebida em fachadas de casas populares. Cumpre esclarecer que o Programa Mais Vida no Morro é uma política pública de cidadania e desenvolvimento sustentável para os morros da cidade do Recife, onde o próprio morador é o protagonista da transformação da sua comunidade. 


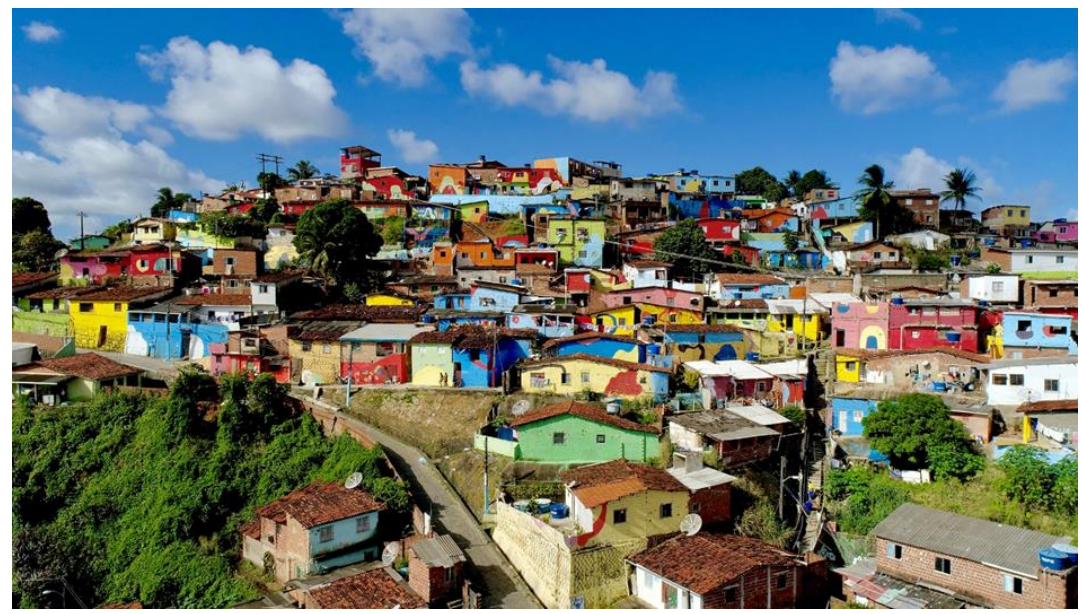

Figura 1. Morro Burity, Bairro da Macaxeira, Recife (PE), Brasil - Mais Vida no Morro. Fonte: Revista Algomais.

Assim, importante se faz definir alguns conceitos, tais como: matiz - refere-se àquela qualidade cromática de uma cor que indicamos pelo seu nome, como azul, azul esverdeado, etc. Ou seja, para alterar o matiz de uma cor devemos misturar outra cor a ela. Se um pouco de verde for misturado com azul, a mudança resultante de azul para azul esverdeado é uma modificaçao de matiz. Luminosidade refere-se à relação de uma cor com o branco e o preto, que indicamos quando dizemos um azul claro ou um azul escuro, ou seja, um azul de maior ou menor luminosidade do que o normal do espectro. Para alterar a luminosidade de uma cor, devemos misturá-la com algo mais claro ou mais escuro que ela mesma. Ao misturar branco ou preto com uma cor, alteramos sua luminosidade sem alterar sua tonalidade. Saturação refere-se à força da cor de um matiz em comparação com um cinza incolor. Indicamos essa comparação quando dizemos um azul brilhante ou um azul opaco. Para alterar a intensidade de uma cor, misturamos a ela algo mais cinza do que realmente é. Ao misturar com uma cor um cinza neutro, que não é nem mais claro nem mais escuro do que a cor dada, ou seja, um cinza que tem a mesma luminosidade da cor, alteramos a intensidade da coloração sem mudar a sua luminosidade ou matiz. Portanto, cada matiz exerce seu efeito particular sobre nós.

O comportamento de nossos próprios olhos, nos processos de fadiga ou alívio, também é, sem dúvida, um fator importante na determinação de nossas preferências por certas cores, tons e combinações. Os objetos coloridos parecem ter uma relação emocional mais próxima conosco do que os objetos de tom neutro. A qualidade adicional da cor ajuda a atrair nossa atenção e a mantê-la por mais tempo. Os matizes não precisam ser opacos para serem agradáveis - os amantes de cores brilhantes, que têm a coragem de sua preferência, são frequentemente confrontados com a teoria de que todas as cores refinadas são necessariamente de intensidade muito reduzida. Portanto, cada matiz exerce seu efeito particular sobre nós. Segundo Sargent (1964), as impressões produzidas por um determinado matiz são tão específicas que até animais e insetos parecem ter preferências marcantes por certas cores, pelo menos seu comportamento é evidentemente influenciado por mudanças de cor. 
É nesse contexto, que a pesquisa em construção se justifica, quando um colorido especial tomou conta do ambiente construído onde, em sua grande maioria, moram usuários de casas populares que terão a oportunidade de avaliar afetivamente suas escolhas.

\section{Questões Teóricas}

Em relação às considerações teóricas, ao ler o texto de Russell (1988), "Affective appraisals of environments", podemos dizer que avaliação afetiva é um aspecto de como alguém interpreta um ambiente. Encontrar um lugar agradável, interessante, estressante, ou semelhante é atribuir a esse lugar uma qualidade afetiva - uma capacidade de alterar o humor. Em outras palavras, dizer que um ambiente é agradável é afirmar que pode produzir o prazer. No entanto, a medição das avaliações afetivas deve ter em conta a sua relatividade. Segundo o autor, indivíduos diferentes podem não avaliar afetivamente o mesmo ambiente, exatamente da mesma maneira. Nem o mesmo indivíduo em momentos diferentes. Então, como podemos avaliar o ambiente em si, para saber o quanto estressante, envolvente, agradável e assim por diante o lugar é? Nesse caminho, o que faz com que os moradores de casas populares optem por pintá-las com cores vibrantes, brilhantes, com diferentes acordes cromáticos?

De acordo com Heath (1988), no seu artigo intitulado "Behavioral and perceptual aspects of the aesthetics of urban environments", há algumas hipóteses ao analisarmos os objetivos ou comportamentos dos indivíduos, a primeira baseia-se nos objetivos diferentes, visto que, objetivos específicos obstruem a interação estética com o meio ambiente. A segunda hipótese sugere que o nosso mapa mental de uma cidade é construído a partir de lugares marcantes. Uma terceira hipótese é a que fala sobre as áreas da frente, as mais visíveis, que devem estar prontas para serem mostradas, já nos bastidores podemos ser nós mesmos.

Muitas pessoas entendem a estética como algo que varia de pessoa para pessoa, embora pesquisas demonstrem que é possível estudar cientifica e quantitativamente atributos estéticos, identificando padrões de preferência (NASAR, 1997). Portanto, quaisquer descobertas sobre preferências humanas, preceitos, cognição, comportamento, variáveis socioculturais, e assim por diante, terão, em princípio, um impacto em nossa compreensão da forma urbana e, por meio disso, influenciarão a maneira como as cidades são organizadas e os critérios usados no planejamento e design (RAPOPORT, 1980).

Em relação à pesquisa ora em desenvolvimento, citamos o fato de que este tema ainda está principiando no ambiente científico, e não foi amplamente abordado na literatura de pesquisa convencional (WAN et al. 2020). Segundo esse mesmo autor, acredita-se que a conotação emocional da cor está principalmente relacionada à luminosidade e croma, e menos relacionado ao matiz. No 
momento, há poucas evidências de pesquisas indicando que a cor pode transmitir emoções, considerando que os estudos sobre a cor urbana têm se concentrado tipicamente em bairros e áreas históricas e culturais. Diz-se que, ainda é impossível provar se impacta nas percepções internas dos residentes urbanos. No entanto, nos últimos anos, temas como planejamento urbano da cor $\mathrm{e}$ psicologia da cor têm estado em ascensão. Além de seus próprios áreas, esses estudos penetraram em campos como arquitetura e design, que refletem seu grande potencial de pesquisa.

Cientificamente, identifica arranjos de cores que podem melhorar o humor humano, para promover a felicidade dos residentes do ambiente urbano e a imagem geral da cidade.

De acordo com Ojo e Kayode (2006), há narrativas sobre a cor ser expressiva porque carrega consigo um simbolismo. Relata ainda, que existem várias teorias sobre o que é o conceito da cor. $\mathrm{O}$ artigo propõe que a teoria do pigmento é a mais relevante quando aplicada ao embelezamento do ambiente urbano. Para os autores, precisamos viver em um ambiente agradável. Há uma sensação de euforia quando os arredores são lugares lindamente pintados e decorados. Em resumo, uma vez que existem contradições e ambiguidades na medição das emoções humanas, e na resposta psicológica à cor é algo que não pode ser medido com precisão.

No entanto, ainda temos que reconhecer a existência de alguns pontos em comum em nossas experiências com cores e embelezamento ambiental. Em um estudo de caso, realizado por Cubukcu et al. (2007) na Turquia, concluiu-se que pouco se sabe sobre a preferência de cores das pessoas para exteriores. Cabe ainda destacar, que a maioria dos estudos usam fotografias coloridas e imagens diversas, ignorando o contexto na preferência da cor.

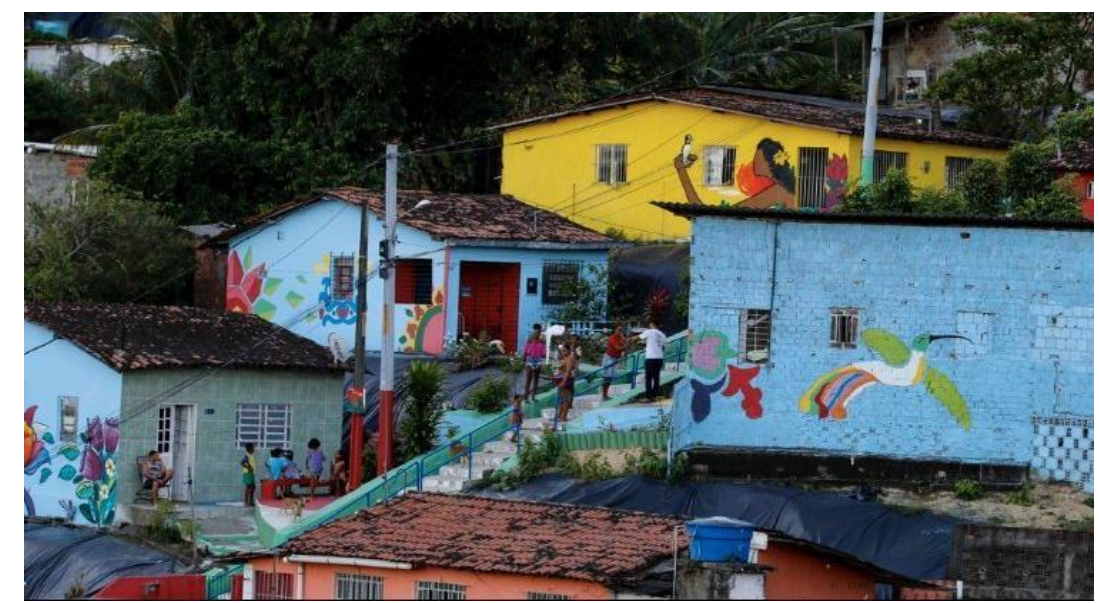

Figura 2. Lagoa Encantada, Bairro do Ibura, Recife (PE), Brasil - Mais Vida no Morro. Fonte: Blog Ponto de Vista.

Na figura 2, percebe-se o colorido especial propiciado pelo Programa Mais Vida no Morro, na comunidade de Lagoa Encantada, no Bairro do Ibura, Recife (PE), Brasil. 


\section{Questões Metodológicas}

Em relação à metodologia, de caráter qualitativo, pretende-se utilizar como método de abordagem a indução científica, e como método de procedimento o estudo de caso, que segundo Yin (2001), tratase de uma investigação empírica em que se examina um fenômeno contemporâneo dentro de seu contexto da vida real, em especial quando não há clareza entre o fenômeno e o contexto.

Através de entrevistas com moradores de casas populares dos morros, sem o emprego de técnicas probabilísticas e dentro de um recorte espacial específico, pretende-se abordar pessoas envolvidas no mutirão do Programa Mais Vida no Morro, além de o levantamento do material prévio ao mutirão, junto aos órgãos municipais e empresas participantes da parceria público-privada.

Pretende-se ainda, como método de procedimento para a coleta de dados, adotar o Sistema de Classificações Múltiplas, adaptado por Canter, Brown e Groat (1985), que consiste em pedir aos participantes para classificar os mesmos elementos diversas vezes, através de critérios definidos por eles (classificações livres) ou pelo pesquisador (classificações dirigidas), para entender seus conceitos/opiniões. As classificações consideram a similaridade de modo que elementos de uma mesma categoria tenham algo distinto das demais. Para isso, contando com o auxílio do programa Adobe Photoshop, pretende-se utilizar imagens de casas populares, com diferentes qualidades cromáticas, como elementos de estímulo para apoiar as classificações.
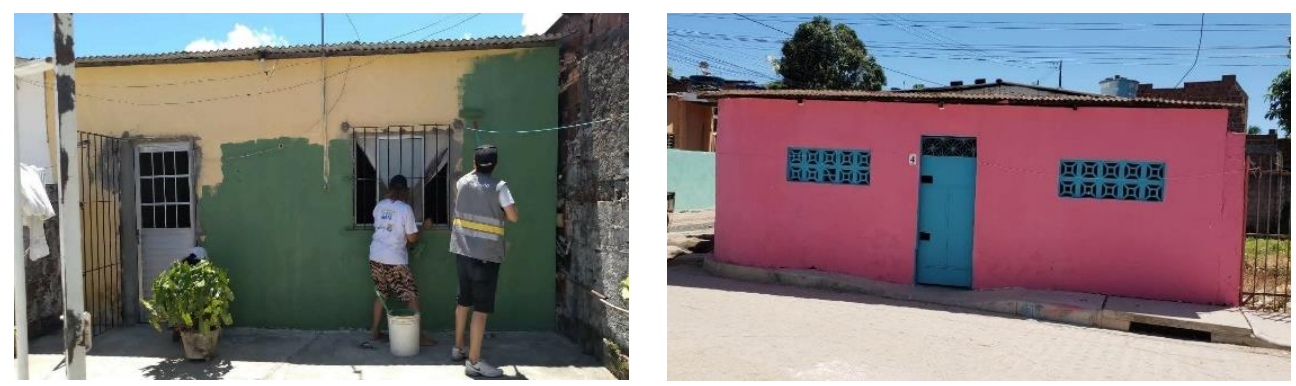

Figuras 3. Intervenção do Programa Mais Vida no Morro, Alto da Bela Vista, Recife-PE Fonte: Arquivo pessoal de Bruno Brayner.
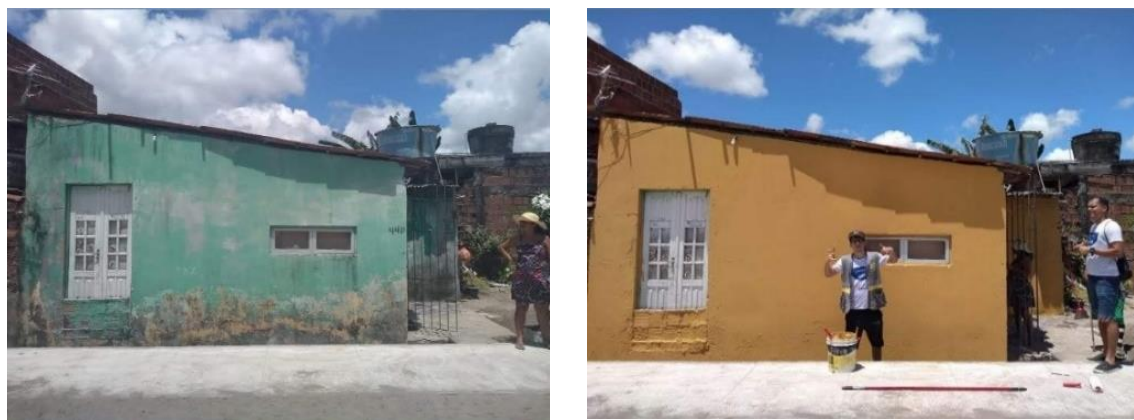

Figuras 4. Antes e Depois da Intervenção do Programa Mais Vida no Morro, no Alto da Bela Vista, Recife-PE Fonte: Arquivo pessoal de Bruno Brayner. 
Nas Figuras 3 e 4, temos registros de como se deram as intervenções do Programa Mais Vida no Morro, na comunidade do Alto da Bela Vista, Nova Descoberta, Recife-PE. Um dos principais objetivos do programa é transformar os espaços urbanos e com isso aumentar o sentimento de pertencimento e o engajamento das comunidades.

Cabe destacar, antes de finalizar, que se pretende registrar os dados coletados em formulários específicos e utilizar a tabela de distribuição das frequências para, a partir das informações quantitativas, interpretá-los e discutir os resultados com base no referencial teórico apresentado.

\section{Referências}

CANTER, D.; BROWN, J.; GROAT, L. Multiple Sorting Procedure for study conceptual systems. In CANTER, D.; BROWN, J.; BRENNER, M. (Org.). Research Interview: use and approaches. London: John Wiley, 1985.

CUBUKCU, E; et al. Hue, saturation, lightness, and building exterior preference: An empirical study in Turkey comparing architects' and nonarchitects' evaluative and cognitive judgments. Wiley Periodicals, Inc., 2007.

GALVÃO; T. F.; PANSANI; T. de S. A.; HARRAD, D. Principais itens para relatar revisões sistemáticas e meta-análises: A recomendação PRISMA. Epidemiol. Serv.Saúde, v.24, n.2, 2015.

Grupo Anima Educação. Manual Revisão Bibliográfica Sistemática Integrativa: a pesquisa baseada em evidências - Belo Horizonte, 2014.

HEATH, T. Behavioral and perceptual aspects of the aesthetics of urban environments. In NASAR, Jack. (Ed.). Environmental aesthetics: theory, research, and application. New York: Cambridge University Press, 1988. p. 6-10.

NASAR, J. L. Visual preferences in urban street scenes. Journal of Cross-Cultural Psychology, Western Washington University, Vol. 15 No. 1, March 1984. p. 79- 93.

NASAR, J. L. The evaluative image of places. In: WALSH, W. B.; CRAIK, K. H.; PRINCE, R. H. 2nd. ed. (Eds.). Person-environment psychology: new directions and perspectives. New Jersey: Lawrence Erlbaum Associates, 2000. p. 117-168.

OJO, B.; KAYODE, F. The role of colour in environmental beautification and urban aesthetics: the Nigerian example. Indoor Built Environ, 2006.

RUSSELL, J. Affective appraisals of environments. In NASAR, Jack. (Ed.). Environmental aesthetics: theory, research, and application. New York: Cambridge University Press, 1988. p. 120-129.

RAPOPORT, A. Human Aspects of Urban Form. Towards a Man - Environment Approach to Urban Form and Design. Urban and regional planning series; v.15, 1980.

SARGENT, W. The Enjoyment and Use of Color. New Youk: Dover Publications, inc., 1964.

WAN, J.; et al. Research on color space perceptions and restorative effects of blue space based on color psychology: Examination of the yijie district of dujiangyan city as an example; International Journal of Environmental Research and Public Health, 2020.

YIN, R. K. Estudo de caso: planejamento e métodos / Robert K. Yin; trad. Daniel Grassi - 2.ed. - Porto Alegre: Bookman, 2001. 